\title{
Androgen Receptor: Evaluation and Correlation with Recurrence and Clinicopathological Parameters in Papillary Urothelial Carcinomas of the Urinary Bladder
}

\author{
Shazia Mumtaz ${ }^{1}$, Zubaida Hussain ${ }^{2}$, Taimoor K. Janjua ${ }^{2}$, Atif Ali Hashmi ${ }^{2}$, Saad Saleem Qureshi ${ }^{2}$, \\ Muhammad Usman Tariq ${ }^{3}$, Naveen Faridi ${ }^{2}$ \\ 1. Pathology, Dow University of Health Sciences, Karachi, PAK 2. Pathology, Liaquat National Hospital and Medical \\ College, Karachi, PAK 3. Pathology, Aga Khan University Hospital, Karachi, PAK
}

Corresponding author: Shazia Mumtaz,shazia_mumtaz12@hotmail.com

\begin{abstract}
Papillary urothelial carcinoma (PUC) is the most common malignant tumor of the urinary bladder. Urothelial tumors are notorious for frequent recurrences and follow a chronic relapsing course in most of the patients. In Pakistan, the incidence of PUC is showing a rising trend. Various immunohistochemical (IHC) markers including androgens have been studied as prognostic and predictive markers in PUC with conflicting results. Androgen is a steroid-based sex hormone and plays an important role in different body organs such as urinary bladder, prostate, muscles, and brain. We aimed to investigate the role of the IHC expression of androgen receptor (AR) as a predictor of recurrence in papillary urothelial carcinoma patients. Eighty-four patients were included in the study. Tissues from the biopsy specimens of these cases were stained with antibodies against AR; $17 \%$ of the cases demonstrated a positive AR IHC expression. The expression was slightly more common in low-grade carcinoma. The AR expression was not significantly associated with clinicopathological features. Recurrence was observed in $49 \%$ of the cases, and it was significantly more common in AR-negative cases (p-value: 0.025). Eighteen out of 19 patients who died of disease were ARnegative, but no statistical significance was observed. We conclude that the IHC expression of AR can be used as a predictive marker for PUC as it correlates with the recurrence rate.
\end{abstract}

Received 12/17/2019 Review began 01/11/2020 Review ended 01/14/2020 Published 01/20/2020

๑) Copyright 2020

Mumtaz et al. This is an open access article distributed under the terms of the Creative Commons Attribution License CC-BY 3.0., which permits unrestricted use, distribution, and reproduction in any medium, provided the original author and source are credited.
Categories: Pathology, Urology, Miscellaneous

Keywords: androgen receptor, urothelial carcinoma, low grade papillary urothelial carcinoma, high grade papillary urothelial carcinoma, recurrence

\section{Introduction}

Papillary urothelial carcinoma (PUC) is the most common malignant tumor of the urinary bladder, comprising $90 \%$ of all primary bladder carcinomas. It is more common in males than in females $[1,2]$. In the US, 80,470 new cases of bladder cancer and 17,670 deaths from bladder cancer were reported in 2019 [1]. Multiple markers have been investigated as diagnostic and prognostic indicators for urothelial carcinomas $[3,4,5]$. Androgen is a steroid-based sex hormone, and it plays an important role in different body organs such as the urinary bladder, prostate gland, muscles, and the brain [6-8]. Androgen is one of the markers whose expression can be seen in normal urothelial mucosa as well as carcinomas of the urinary bladder [9].

According to Globacon 2018, bladder cancer ranks eighth among all malignancies in Pakistan, with 4,610 new cases and 2,614 deaths reported in 2018 [10]. Bladder cancers carry high recurrence rates (10-year recurrence rate: $74.3 \%$ ), and hence the patients need life-long monitoring [11]. Urothelial cancers top the list of tumors that cause the most economic burden since they reportedly incur the highest lifetime costs per patient among all malignancies [12]. As a result, further studies are urgently required to develop markers, which can aid in the separation of cases that are less likely to recur and thus contribute to the reduction of treatment costs. The role of the androgen receptor (AR) status as a predictive marker of PUC has been assessed in different populations worldwide [13-21]. However, no such assessment has been performed in the Pakistani population to our knowledge. This paucity of data relating to the Pakistani population prompted us to investigate the correlation of AR expression with recurrence in urothelial tumors in patients at a hospital in Karachi, Pakistan.

\section{Materials And Methods}

\section{Study population and settings}

This retrospective study was conducted on patients diagnosed with low- or high-grade PUC between July 2009 and June 2019. In all cases, follow-up data was determined through data available for at least one year for patient survival or reported deaths from carcinoma, depending on whichever came first. The study was conducted at the Department of Histopathology, Liaquat National Hospital and Medical College, Karachi, Pakistan. Institutional board approval was taken from the Research and Ethics Committee of the hospital. 


\section{Methodology}

The surgical pathology slides at the Department of Pathology reported as PUC during the study period and paraffin blocks were reviewed. The hematoxylin and eosin section for each case was reviewed by two pathologists for confirmation of the original diagnosis based on the 2004 WHO/International Society of Urological Pathology Classification. In selected cases, immunohistochemistry (IHC) was performed using a monoclonal mouse anti-AR antibody on paraffin-embedded tissue sections of transurethrally resected tissue samples. The Dako REAL EnVision Detection System, Peroxidase/DAB, Rb/Mo (Dako, Denmark) was used for IHC staining. Briefly, 5 - $\mu \mathrm{m}$ serial sections were cut for formalin-fixed, paraffin-embedded (FFPE) tissue onto Superfrost slides (Thermo Scientific, Germany). The sections were deparaffinized in xylene and rehydrated in graded series of ethanol (Merck, Germany). Heat-induced antigen retrieval was performed in a 10-mM citrate buffer (PH6.0) for one hour in a boiling water bath. Endogenous peroxidase activity was blocked by immersing slides in $0.3 \% \mathrm{w} / \mathrm{v} \mathrm{H} 2 \mathrm{O} 2$ room temperature for 10 minutes. Next, the antihuman AR antibody (mouse monoclonal IgG, clone AR 441; Dako diluted 1:50) was applied for four hours at room temperature. After three washes for five minutes each in phosphate-buffered saline (PH7.4), horseradish peroxidase (HRP)-labeled secondary antibody was applied for one hour at room temperature. After washing, the substrate was added and DAB was used for visualization. Hematoxylin was used for counterstaining. The primary antibody was replaced by phosphate-buffered solution and prostatic tissue served as negative and positive controls respectively.

\section{Scoring}

The AR expression was assessed by counting 500 tumor cells in the most immune-reactive area of the slides. The AR expression was considered positive when $>10 \%$ of the tumor cells showed nuclear staining [13].

\section{Statistical analysis}

The Statistical Package for Social Sciences version 20 (SPSS; IBM, Armonk, NY) was used to analyze data. Frequencies and percentages were computed for categorical variables. Mean and standard deviations were computed for quantitative variables. A chi-square test was applied to investigate the association of categorical variables. The odds ratio (OR) was calculated by univariate binary logistic regression. A p-value of $\leqslant 0.05$ was considered statistically significant. Overall survival was taken as the time from surgical excision till death or the last follow-up, and disease-free survival was defined as the time between surgical excision and local recurrence or distant metastasis, death, or the last follow-up.

\section{Results}

A total of 84 PUC patients were included in our study, of which 66 were males (78.6\%) and 18 females (21.4\%). The mean age was 64.30 ( \pm 15.34 ) years (range: 8-92 years). Both low- and high-tumor grade PUC groups comprised 42 patients each. The mean follow-up duration was $13.32( \pm 10.55)$ months (range: 140 months). Recurrence was defined as the appearance of new growth in the bladder and/or ureter at least six months after the complete removal of initial growth. The recurrent growth was histologically confirmed to be PUC. Recurrence was noted in 41 (48.8\%) patients. In our study, positive staining of AR was observed in 14 cases (16.7\%). Detailed clinicopathological features of patients are presented below (Table 1). 


\section{Cureus}

\begin{tabular}{|c|c|}
\hline & Mean \\
\hline Age, years & $64.30( \pm 15.34)^{\star}$ \\
\hline Follow-up, months & $13.32( \pm 10.55)^{\star}$ \\
\hline Recurrence, months & $12.78( \pm 10.35)^{\star}$ \\
\hline \multicolumn{2}{|l|}{ Gender, n (\%) } \\
\hline Male & $66(78.6)$ \\
\hline Female & $18(21.4)$ \\
\hline \multicolumn{2}{|l|}{ Tumor grade, $\mathrm{n}(\%)$} \\
\hline Low & $42(50)$ \\
\hline High & $42(50)$ \\
\hline \multicolumn{2}{|c|}{ Deep muscle invasion, $\mathrm{n}(\%)$} \\
\hline Present & $10(11.9)$ \\
\hline Absent & $74(88.1)$ \\
\hline \multicolumn{2}{|c|}{ Androgen receptor expression, $\mathrm{n}(\%)$} \\
\hline Positive & $14(16.7)$ \\
\hline Negative & $70(83.3)$ \\
\hline \multicolumn{2}{|l|}{ Recurrence, n (\%) } \\
\hline Yes & $41(48.8)$ \\
\hline No & $43(52.2)$ \\
\hline \multicolumn{2}{|l|}{ Survival status, $\mathrm{n}(\%)$} \\
\hline Alive & $65(77.4)$ \\
\hline Dead & $19(22.6)$ \\
\hline
\end{tabular}

\section{TABLE 1: Clinicopathological profile of patients}

${ }^{\star}$ Figures in parentheses represent standard deviation

Among AR-negative patients, recurrence was noted in 38 (58\%) patients, while among AR-positive patients, recurrence was observed in only 3 (21.4\%) patients. We found a significant association between AR-receptor negativity and recurrence (p: 0.025). AR was positive in 8 (19\%) low-grade and $6(14.3 \%)$ high-grade carcinomas; there was no significant association between AR expression and tumor grade (p: 0.558) (Table 2). 


\section{Cureus}

\begin{tabular}{|c|c|c|c|c|}
\hline & & \multicolumn{2}{|c|}{ Androgen receptor status, n (\%) } & \multirow{2}{*}{ P-Value } \\
\hline & & Positive & Negative & \\
\hline \multirow{2}{*}{ Recurrence } & Yes & $3(21.4)$ & $38(54)$ & \multirow{2}{*}{$0.025^{\star}$} \\
\hline & No & $11(78.6)$ & $32(45)$ & \\
\hline \multirow{2}{*}{ Tumor grade } & Low & $8(19)$ & $34(81)$ & \multirow{2}{*}{0.558} \\
\hline & High & $6(14.3)$ & $36(85)$ & \\
\hline
\end{tabular}

TABLE 2: Association between androgen receptor status and recurrence

*Statistically significant

No significant difference was found in AR-positive expression with respect to gender, lamina propria invasion, or deep muscle invasion (Table 3).

\begin{tabular}{|c|c|c|c|c|}
\hline & Frequency, $\mathbf{n}(\%)$ & Odds ratio & P-value & $95 \% \mathrm{Cl}$ \\
\hline \multicolumn{5}{|l|}{ Age groups } \\
\hline$\leq 50$ years & 17 (20.2) & 1 & & \\
\hline$>50$ years & 67 (79.8) & 0.26 & 0.210 & $0.032-2.139$ \\
\hline \multicolumn{5}{|l|}{ Gender } \\
\hline Male & 66 (78.6) & 1 & & \\
\hline Female & 18 (21.4) & 1.778 & 0.480 & $0.360-8.784$ \\
\hline \multicolumn{5}{|l|}{ Tumor grade } \\
\hline Low & $42(50)$ & 1.412 & 0.559 & $0.444-4.493$ \\
\hline High & $42(50)$ & 1 & & \\
\hline \multicolumn{5}{|c|}{ Invasion In lamina propria } \\
\hline Present & 70 (83.3) & 1.292 & 0.764 & $0.244-6.849$ \\
\hline Absent & $14(16.7)$ & 1 & & \\
\hline \multicolumn{5}{|c|}{ Deep muscle invasion } \\
\hline Present & 10 (15.5) & 2.711 & 0.149 & $0.700-10.504$ \\
\hline Absent & 74 (84.5) & 1 & & \\
\hline \multicolumn{5}{|l|}{ Recurrence } \\
\hline Yes & $41(48.80)$ & 0.230 & 0.034 & $0.059-0.895$ \\
\hline No & $43(51.20)$ & 1 & & \\
\hline
\end{tabular}

TABLE 3: Parameters showing independent predictors of androgen receptors

Deaths occurred in 19 cases, of which 18 cases were AR-negative. Recurrence was less likely to develop in females in comparison to males (OR: 0.321), while older patients were more likely to develop recurrence in comparison with younger patients (OR: 2.78) (Table 4). 


\section{Cureus}

\begin{tabular}{|c|c|c|c|c|}
\hline & Frequency, n (\%) & Odds ratio & P-value & $95 \% \mathrm{Cl}$ \\
\hline \multicolumn{5}{|l|}{ Age groups } \\
\hline$\leq 50$ years & 17 (20.2) & 1 & & \\
\hline$>50$ years & 67 (79.8) & 2.787 & 0.080 & $0.884-8.789$ \\
\hline \multicolumn{5}{|l|}{ Gender } \\
\hline Male & 66 (78.6) & 1 & & \\
\hline Female & 18 (21.4) & 0.321 & 0.050 & $0.103-1.002$ \\
\hline \multicolumn{5}{|l|}{ Tumor grade } \\
\hline Low & $42(50)$ & 1.100 & 0.827 & $0.467-2.589$ \\
\hline High & $42(50)$ & 1 & & \\
\hline \multicolumn{5}{|c|}{ Invasion In lamina propria } \\
\hline Present & $10(15.5)$ & 0.947 & 0.936 & $0.253-3.549$ \\
\hline Absent & 74 (84.5) & 1 & & \\
\hline \multicolumn{5}{|c|}{ Deep muscle invasion } \\
\hline Present & $10(15.5)$ & 0.543 & 0.323 & $0.162-1.822$ \\
\hline Absent & $74(84.5)$ & 1 & & \\
\hline \multicolumn{5}{|c|}{ Androgen receptor } \\
\hline Present & $14(16.7)$ & 0.230 & 0.034 & $0.059-0.895$ \\
\hline Absent & $70(83.3)$ & 1 & & \\
\hline
\end{tabular}

\section{TABLE 4: Odds ratio showing independent predictors of recurrence}

Cl: confidence interval

\section{Discussion}

AR is a ligand inducible transcription factor that mediates the biological effects of androgen hormone [14]. Androgen hormone is a sex-steroid hormone present in most body organs including the urinary bladder [9]. Multiple studies have investigated the association between androgens and bladder cancer pertaining to different aspects including tumor grade, recurrence rate, and clinical stage $[4,5,15]$. Papillary urothelial carcinomas are male-predominant carcinomas and this observation has also been highlighted in various studies, indicating the role of androgen in urothelial carcinomas $[5,16]$.

In Pakistan, bladder cancer incidence is rising [10]. In our study, we evaluated the AR expression in bladder cancer patients and found that AR-positive expressions correlated with decreased risk of recurrence. We also found higher recurrence in males and the elderly.

Androgen hormone-binding activates AR leading to the progression of bladder cancers [17]. Androgen hormone downregulation by using anti-androgens has a protective effect in PUC. In a study done on patients diagnosed with prostate carcinoma, androgen-deprivation therapy was given by androgen receptor blockers, resulting in decreased androgen hormone levels. With long-term follow-ups, it was observed that androgen deprivation decreased the incidence of bladder cancer [18].

Androgen hormone and its receptor have been found to be strongly associated with bladder cancer progression and tumorigenesis $[17,19,20]$. In a large multinational cohort study, no association was found between the loss of AR and clinical outcomes. Investigators performed a study at two different city hospitals and, in both the centers, no association of AR was noted with respect to tumor grade, type, stage, and gender of patients $[15,21]$. The loss of AR expression was seen in high-grade urothelial cancers and invasive tumors, while no association was noted between AR expressions and tumor recurrence [13].

A multi-institutional based study on a large number of patients compared tumor grade with androgen status. 
It found no association between tumor grade and AR status [15]. This was similar to other findings in our study, while another study reported a negative association between AR status and tumor grade and invasiveness [4].

In our opinion, such varied results in studies can be attributed to multiple factors, such as sampling and laboratory techniques. In sampling techniques, factors that can influence could include sample size and genetic make-up of the population being studied. The laboratory factors that can contribute include the fixation time of tissues in formalin, the use of antibodies from different companies, methods of dilution, different cut-off parameters used for positive and negative results, and IHC vs molecular-based techniques.

Urinary bladder carcinomas belong to a group of tumors that have a high recurrence rate; therefore, regular surveillance with urine cytology and cystoscopy is an essential part of treatment protocol [22]. There is an urgent need to develop markers that can serve as prognostic and predictive indicators in bladder tumors. As regular surveillance is costly, the AR status can aid in this regard for patient selection. Going forward, the AR status can be used to give endocrine therapy in selected patients [23]. We recommend larger studies to establish correlations with staging and concurrent application of IHC along with other molecular-based techniques.

Our study strengths include a large sample size and patient follow-up. Limitations were the usage of IHC methodology and transurethral resection samples.

\section{Conclusions}

We are able to conclude that positive expression of AR correlates with decreased recurrence rate in PUC, irrespective of histologic grade. AR can be utilized as a new predictive marker in urothelial carcinomas, especially in developing countries.

\section{Additional Information \\ Disclosures}

Human subjects: Consent was obtained by all participants in this study. Ethical Review Committee, Liaquat National Hospital and Medical College, Karachi, Pakisrtan issued approval Ref: App\#0492-2019-LNH-ERC. The Ethical Review Committee of Liaquat National Hospital and Medical College, Karachi has reviewed and approved this study. . Animal subjects: All authors have confirmed that this study did not involve animal subjects or tissue. Conflicts of interest: In compliance with the ICMJE uniform disclosure form, all authors declare the following: Payment/services info: All authors have declared that no financial support was received from any organization for the submitted work. Financial relationships: All authors have declared that they have no financial relationships at present or within the previous three years with any organizations that might have an interest in the submitted work. Other relationships: All authors have declared that there are no other relationships or activities that could appear to have influenced the submitted work.

\section{Acknowledgements}

We would like to thank the Department of Histopathology, Liaquat National Medical College, Karachi.

\section{References}

1. National Cancer Institute Surveillance and Epidemiology and End Results Program. Cancer stat facts: bladder cancer. (2019). Accessed: January 14, 2020: https://seer.cancer.gov/statfacts/html/urinb.html.

2. Negri E, La Vecchia C: Epidemiology and prevention of bladder cancer . Eur J Cancer Prev. 2001, 10:7-14. 10.1097/00008469-200102000-00002

3. Boorjian S, Ugras S, Mongan NP, Gudas LJ, You X, Tickoo SK, Scherr DS: Androgen receptor expression is inversely correlated with pathologic tumor stage in bladder cancer. Urology. 2004, 64:383-388. 10.1016/j.urology.2004.03.025

4. Miyamoto H, Yao JL, Chaux A, et al.: Expression of androgen and oestrogen receptors and its prognostic significance in urothelial neoplasm of the urinary bladder. BJU Int. 2012, 109:1716-1726. 10.1111/j.1464 410X.2011.10706.X

5. Mumtaz S, Hashmi AA, Hasan SH, Edhi MM, Khan M: Diagnostic utility of p53 and CK20 immunohistochemical expression grading urothelial malignancies. Int Arch Med. 2014, 7:36. Accessed: January 19, 2020: https://www.ncbi.nlm.nih.gov/pubmed/25089155. 10.1186/1755-7682-7-36

6. Hutson JM, Hasthorpe S, Heyns CF: Anatomical and functional aspects of testicular descent and cryptorchidism. Endocr Rev. 1997, 18:259-280. 10.1210/edrv.18.2.0298

7. MacLean HE, Moore AJ, Sastra SA, et al.: DNA-binding-dependent androgen receptor signaling contributes to gender differences and has physiological actions in males and females. J Endocrinol. 2010, 206:93-103. 10.1677/JOE-10-0026

8. Sato T, Matsumoto T, Kawano H, et al.: Brain masculinization requires androgen receptor function. Proc Natl Acad Sci U S A. 2004, 101:1673-1678. 10.1073/pnas.0305303101

9. Wilson CM, McPhaul MJ: A and B forms of the androgen receptor are expressed in a variety of human tissues. Mol Cell Endocrinol. 1996, 120:51-57. 1016/0303-7207(96)03819-1 
10. International Agency for Research on Cancer, WHO. Pakistan. Source: Globocan 2018 . (2018). Accessed: January 14, 2020: https://gco.iarc.fr/today/data/factsheets/populations/586-pakistan-fact-sheets.pdf.

11. Chamie K, Litwin MS, Bassett JC, et al.: Recurrence of high-risk bladder cancer: a population-based analysis . Cancer. 2013, 119:3219-3227.10.1002/cncr.28147

12. Svatek RS, Hollenbeck BK, Holmäng S, Lee R, Kim SP, Stenzl A, Lotan Y: The economics of bladder cancer: costs and considerations of caring for this disease. Eur Urol. 2014, 66:253-262. doi: 10.1016/j.eururo.2014.01.006

13. Tuygun C, Kankaya D, Imamoglu A, Sertcelik A, Zengin K, Oktay M, Sertcelik N: Sex-specific hormone receptors in urothelial carcinomas of the human urinary bladder: a comparative analysis of clinicopathological features and survival outcomes according to receptor expression. Urol Oncol. 2011, 29:43-51. 10.1016/j.urolonc.2009.01.033

14. Torres-Estay V, Carreño DV, San Francisco IF, Sotomayor P, Godoy AS, Smith GJ: Androgen receptor in human endothelial cells. J Endocrinol. 2015, 224:R131-137. 10.1530/JOE-14-0611

15. Mir C, Shariat SF, Van Der Kwast TH, et al.: Loss of androgen receptor expression is not associated with pathological stage, grade, gender or outcome in bladder cancer: a large multi-institutional study. BJU Int. 2011, 108:24-30. 10.1111/j.1464-410X.2010.09834.x

16. Imada S, Akaza H, Ami Y, Koiso K, Ideyama Y, Takenaka T: Promoting effects and mechanisms of action of androgen in bladder carcinogenesis in male rats. Eur Urol. 1997, 31:360-364. 10.1159/000474484

17. Izumi K, Zheng Y, Hsu JW, Chang C, Miyamoto H: Androgen receptor signals regulate UDPglucuronosyltransferases in the urinary bladder: a potential mechanism of androgen-induced bladder carcinogenesis. Mol Carcinog. 2013, 52:94-102. 10.1002/mc.21833

18. Izumi K, Taguri M, Miyamoto H, et al.: Androgen deprivation therapy prevents bladder cancer recurrence. Oncotarget. 2014, 5:12665-12674. Accessed: January 19, 2020: https://www.ncbi.nlm.nih.gov/pubmed/25557268. 10.18632/oncotarget.2851

19. Miyamoto H, Yang Z, Chen YT, et al.: Promotion of bladder cancer development and progression by androgen receptor signals. J Natl Cancer Inst. 2007, 99:558-568. 10.1093/jnci/djk113

20. Nam JK, Park SW, Lee SD, Chung MK: Prognostic value of sex-hormone receptor expression in non-muscleinvasive bladder cancer. Yonsei Med J. 2014, 55:1214-1221. 10.3349/ymj.2014.55.5.1214

21. Kashiwagi E, Fujita K, Yamaguchi S, et al.: Expression of steroid hormone receptors and its prognostic significance in urothelial carcinoma of the upper urinary tract. Cancer Biol Ther. 2016, 17:1188-1196. 10.1080/15384047.2016.1235667

22. Burger M, Oosterlinck W, Konety B, et al.: ICUD-EAU International Consultation on Bladder Cancer 2012: non-muscle-invasive urothelial carcinoma of the bladder. Eur Urol. 2013, 63:36-44. 10.1016/j.eururo.2012.08.061

23. Izumi K, Ito Y, Miyamoto H, et al.: Expression of androgen receptor in non-muscle-invasive bladder cancer predicts the preventive effect of androgen deprivation therapy on tumor recurrence. Oncotarget. 2016, 22:14153-14160. Accessed: January 19, 2020: https://www.ncbi.nlm.nih.gov/pubmed/26885620. 10.18632/oncotarget.7358 